\title{
Evaluation of the Philippine National Foreign Language Program in Public Secondary Schools
}

\author{
Jocelyn Dr Andaya, Tina Amor Buhat, Ana Marie Calapit, Glenne Delos Trinos, \\ Rosa Ligaya Domingo, Wenda Fajardo, Ayette Ferriols, Riza Gusano, Anna Maria Patricia Santos, \\ Samuel Soliven
}

Department of Education (DepEd), Bureau of Curriculum Development (BCD), Manila, Philippines

Email address:

riza.gusano@deped.gov.ph (R. Gusano)

\section{To cite this article:}

Jocelyn Dr Andaya, Tina Amor Buhat, Ana Marie Calapit, Glenne Delos Trinos, Rosa Ligaya Domingo, Wenda Fajardo, Ayette Ferriols, Riza Gusano, Anna Maria Patricia Santos, Samuel Soliven. Evaluation of the Philippine National Foreign Language Program in Public Secondary Schools. International Journal of Language and Linguistics. Vol. 8, No. 6, 2020, pp. 240-245. doi: 10.11648/j.ij11.20200806.11

Received: March 27, 2020; Accepted: April 22, 2020; Published: November 4, 2020

\begin{abstract}
The study evaluated the implementation of the Philippine National Foreign Language Program (Special Program in Foreign Language [SPFL]). A descriptive research design was employed to identify the following: (1) the profile of SPFL students and graduates and (2) the graduates' current status; (3) the teachers' and school heads' assessment of the program and (4) the difference between the two; and (5) the challenges encountered in the implementation of SPFL. The current study found varied reasons for unemployment among graduates, but there was a consensus among student- and graduate-participants that the program is satisfactory in terms of its objectives and curriculum. Teachers reported to have encountered serious problems in SPFL implementation while the principals described the problems as only moderately serious. A model for implementing the SPFL curriculum was then developed based on the results of the study. This includes four main agents of implementation: administrators, teachers, learners and support groups, each with respective tasks to practice.
\end{abstract}

Keywords: Foreign Language, Implementation Practices, Curriculum Model

\section{Introduction}

The vast development brought about by modern technology, specifically communication technology, has caused significant influx in the number of international, business, and social communication transactions [3, 13]. This, in turn, highlights the importance of foreign language as one of the primary engines of globalization. Effective communication is key to sustaining an interconnected world, making foreign language skills the "ultimate $21^{\text {st }}$ century social skill [12]" and global competency. But more than its contribution to the development of global citizenship, the ability to use a foreign language offers many personal benefits to the language learners themselves. The World Economic Forum [14] identifies tolerance as one of the affective advantages to foreign language learning as it fosters perspective-taking skills and cultural intelligence or the ability to understand and be flexible to different world views, hence allowing for easy transition to and engagement in varied new situations. Multilingual learners, furthermore, have been consistently found to be more cognitively advanced displaying creativity, problem-solving, divergent thinking, and social skills [9]. Parallel to this, Abbott (2018) [1] reports that academic gains in all learning areas or subjects are experienced by students who participate in foreign language programs.

In light of the personal and societal significance of foreign language education, the Philippine Education Department (DepEd) put forth the Special Program in Foreign Language (SPFL), which is anchored on various legal bases - the most relevant of which is Republic Act 10533 or the Enhanced Basic Education Act of 2013 [7, 15].

DepEd Memorandum No. 560, s. 2008 launched the SPFL in public and private secondary schools, which were encouraged to offer the following foreign languages: Spanish, French, and Japanese in 2009; German in 2010; Chinese Mandarin in 2011; and Korean in 2016 [4, 5, 15]. The objective of the SPFL is to prepare students for higher education and employment with competence in a foreign language, and to engage in meaningful interactions in a 
linguistically and culturally diverse global workplace. The move to further increase each of the region's ownership of SPFL by taking part in the cost-sharing scheme and intensifying support for teachers' professional foreign language development is expressed by DepEd Order No. 5, s. 2015 or "Integration of travel expenses of SPFL teachers attending local training on teaching foreign language in the region/division/school budget [6]."

The current study evaluates the implementation of the Philippines' National Foreign Language Program or the Special Program in Foreign Language in the public secondary schools, so that the problems encountered may be addressed. The study specifically focuses on (1) the profile of SPFL students and graduates and (2) the graduates' current status; (3) the teachers' and school heads' assessment of the program and (4) the difference between the two; and (5) the challenges encountered in the implementation of SPFL. The results of the study were then used to develop a model for the improved implementation of the program.

\section{Methods}

The research utilized a descriptive research design. The Raosoft sample size calculator at 5 percent margin of error was employed in order to determine the appropriate sample size of teachers and school heads. The teachers from SPFL implementing public secondary schools of various regions in the Philippines were considered in the study. A total of 203 school heads, 243 teachers, 3,554 currently enrolled students, and 409 graduates served as the research participants.

A questionnaire was developed to gather data from the respondents. It was validated by five experts in SPFL implementation. After which, the questionnaire was revised and reproduced. Copies were distributed for dry run among five principals and ten teachers from schools which were not part of the actual study. Interview guides for the focus group discussion were also utilized to triangulate the data gathered. Weighted mean and T-test were used to treat quantitative data while transcriptions were used as qualitative data.

\section{Results and Discussion}

\subsection{Profile of SPFL Graduates}

$37.89 \%$ of graduates took up Spanish; $5.87 \%$ took up German; $11.74 \%$ took up French; $26.40 \%$ took up Chinese; and $18.09 \%$ took up Japanese.

a) On gender

282 or $63.23 \%$ of graduates are females while 127 or $28.48 \%$ are males.

b) On employment status

Out of the 409 respondents, $49.14 \%$ or 201 are currently engaged in different kinds of work while $50.86 \%$ or 208 are unemployed.

c) On the nature of work

$23.88 \%$ of employed SPFL graduates work as teachers. Other graduates work as interpreters or translators and online tutors, and tour guides, which consisted of $12.44 \%$ and $5.47 \%$ of the respondents, respectively. $4.98 \%$ SPFL graduates are employed in business process outsourcing (BPO) companies; $3.98 \%$ in sales; $2.99 \%$ in journalism; $2.49 \%$ in IT companies; and $0.99 \%$ in caring services, research and administration.

$29.85 \%$ of these jobs are reported to be permanent while $27.86 \%$ are contractual or probationary. The other 49 respondents, which comprised the second highest percentage of $24.38 \%$, did not respond.

d) On the assistance provided

The participants report that assistance was most evident during career planning, which has the highest percentage of 51.57. This is followed by assistance in pursuing higher education with $50.67 \%$, assistance with middle skills development garnered $57.18 \%$, and entrepreneurship with $29.60 \%$.

e) On the reasons for unemployment

$84.62 \%$ of SPFL graduates claim that their reason for unemployment was due to their enrolment in college while $40.87 \%$ or 85 of them reported that their reason for unemployment was not found in the specified options in the questionnaire. $16.35 \%$ or 34 of the graduates did not exert effort to look for a job while $12.98 \%$ or 27 claimed that there was no job opportunity for them. $11.06 \%$ or 23 respondents conveyed that they lack experience to look for a job; $10.58 \%$ or 22 cited family concerns; and $9.13 \%$ remained unemployed due to health-related reasons.

\subsection{Satisfaction with Foreign Language Use and Assessment Procedures}

The highest weighted mean of 4.18 , with the verbal interpretation of satisfactory, was reported for the item, "the teacher presents in the classroom for discussion." The gaps between and among the weighted mean results are almost the same with a composite mean of 4.01. The least weighted mean, on the other hand, is 3.75. Most of the students express agreement $(\mathrm{M}=4.09)$ that their obtained grade accurately reflects their performance. Moreover, they also agreed $(\mathrm{M}=4.02)$ that the tasks given to them are coherent with the course objectives, contents, and activities in class. Similarly, they agreed that the assessment given by the teacher determines their real skills. The students also agree $(\mathrm{M}=4.00)$ that the teacher presents the criteria prior to the evaluation and assessment process. Students report that assessment tasks are presented at the beginning of the course $(M=3.99)$. Finally, they claim that the four language skills were assessed $(\mathrm{M}=3.94)$.

\subsection{Assessment on the Implementation Status of Special Program in Foreign Language (SPFL) in the Public Secondary Schools}

a) Objectives

The composite mean of the assessment on objectives is 3.73 for principals, which is verbally interpreted as Very Good, while the teachers' assessment is 3.76 , which is also Very Good. 
b) Curriculum Implementation

The composite mean of the assessment on curriculum implementation for Grade 7 is 3.49 for principals, which is verbally interpreted as Good, while the teachers' assessment is 3.56, which is also Very Good. For Grade 8, the principals' assessment is 3.31, which is Good, while the teachers' assessment is 3.43, which is also Good. For Grade 9, the principals' assessment is 3.32, which is Good, while the teachers' assessment is 3.26 , which is also Good. Finally, the principals' assessment is 3.24, which is Good, while the teachers' assessment is 3.31, which is also Good.

c) Instruction

The composite mean of the assessment on objectives is 3.52 for principals, which is verbally interpreted as Often, while the teachers' assessment is 3.65 , which is also Often.

d) Assessment

The principals' rating on formative assessment is 3.61, which is Often, while the teachers' assessment is 3.65 , which is also Often. In terms of summative assessment, the principals' rating is 3.73 , which is verbally interpreted as Often, while the teachers' assessment is 3.80 , which is verbally interpreted as Often.

e) Human Resource

There are 159 qualified faculty, majority of which or 140 teachers have at least two teaching preparations. 146 teachers reported that SPFL has Functional Development programs; 190 teachers attended seminars; 175 teachers reported that SPFL was monitored; and 204 teachers have regular teaching loads.

\section{f) Facilities/Materials/Equipment}

School heads and teachers both claim that there is a dire need to provide state of the art facilities for the effective implementation of SPFL. Results showed the distribution of printed materials according to principals' response: Printed books with $\mathrm{f}=169$ or $83.25 \%$; printed journals with $\mathrm{f}=27$ or $13.30 \%$; printed charts with $\mathrm{f}=50$ or $24.63 \%$; printed newspapers with $\mathrm{f}=12$ or $5.91 \%$ and printed dictionaries with $\mathrm{f}=53$ or $26.11 \%$. Similarly, in terms of teachers' turf, accorded are the following responses: Printed books with $\mathrm{f}=185$ or $76.13 \%$; printed journals with $\mathrm{f}=29$ or $11.93 \%$; printed charts with $\mathrm{f}=63$ or $25.93 \%$; printed newspapers with $\mathrm{f}=24$ or $9.88 \%$ and printed dictionaries with $\mathrm{f}=74$ or $30.45 \%$.

It is found out in the study that the following indicators constitute the responses yielded: In terms of principal's turf 1.) speech laboratory with $\mathrm{f}=23$ or $11.33 \%$ 2.) Amphitheater with $\mathrm{f}=8$ or $3.94 \%$ 3.) blackboard with $\mathrm{f}=188$ or 92.614 .) whiteboard with $\mathrm{f}=174$ or $85.71 \% 5$.) chalks with $\mathrm{f}=190$ or $93.60 \%$ 6.) erasers with $\mathrm{f}=195$ or 96.06 and 7.) boardmarkers with $\mathrm{f}=179$ or $88.18 \%$. Similarly, in terms of teacher's turf; 1) speech laboratory with $\mathrm{f}=23$ or $9.47 \%$ 2.) Amphitheater with $\mathrm{f}=8$ or $3.29 \%$ 3.) blackboard with $\mathrm{f}=226$ or 93.004 4) whiteboard with $\mathrm{f}=193$ or $79.42 \% 5$.) chalks with $\mathrm{f}=227$ or $93.42 \% 6$.) erasers with $\mathrm{f}=235$ or 96.71 and 7 .) boardmarkers with $\mathrm{f}=205$ or $84.36 \%$.

\subsection{Difference between the Assessment of Teachers and Principals on the Implementation Status of SPFL}

a) There is no significant difference between the assessment of teachers and principals on the impact of the SPFL in terms of its objectives. Since the computed p-value of .947 is higher than the .05 level of significance, the null hypothesis is not rejected.

b) In terms of the SPFL curriculum from Grade 7 to 10 , it is important to note that a p-value of .074 with that of $.000, .017$, and .015 may be interpreted in relation to the difficulty of the language skills to be learned.

c) Instruction, on the other hand, yields a p-value of .000, which entails the researcher to conclude that direct contact with the students has a significant impact on the learning of a foreign language. The area of assessment, in contrast, yields no significant difference both on the aspect of the formative and written, with a p-value of .213 and .565.

d) Human resource yielded a p-value of .073 and a computed t-value of 1.791 which leads to a "Failed to Reject" decision which means that no significant difference was identified between variables.

e) Assessment yielded p-value of .213 and computed tvalues of -1.248 for formative assessment and $.565 \mathrm{p}$ value and -0.576 computed t-value for written assessment that are both not significant which means that there is no difference between variables.

f) Facilities is with a p-value of .75 and computed tvalues of 1.791 which means that there is no significant difference between variables relative to facilities.

\subsection{Problems Encountered in the Implementation of SPFL}

Teachers reported that there is a serious problem in SPFL implementation with a weighted mean of 3.34 , while the principals describe the challenges in the program implementation as moderately serious, with a weighted mean of 2.86 .

\subsection{Discussion of Results}

The results of the study show that stakeholders, particularly students, teachers and principals, are generally satisfied with the implementation of SPFL, with majority of the student-respondents reporting that they observe good teaching and assessment practices, and teacher- and principal-participants reporting that enough support for program implementation is given through the provision of activities for professional development and distribution of resources.

However, some of the findings provide important implications for the program. First, it was noted that a good number of students proceeded with their college education upon graduating from SPFL. This raises the question of whether or not their pursuit of the foreign language was continued. If yes, how was the program helpful in higher education? If not, what happens to what was learned in the program? The ultimate goal of SPFL is to produce learners 
who are communicatively competent in the foreign language they specialize in, and able to display their knowledge of the language in the workplace. But how will this be achieved if the student is not able to exemplify this skill? With the program goal and the data gathered in mind, to say that SPFL is successful may not be claimed entirely.

The second question raised above poses an even more important issue which may have grave consequences. If the process of learning and using a foreign language is discontinued, it is presupposed that the language will be forgotten [8]. This is known as language attrition - a concept that has expanded to include the loss of both the native language and second or foreign language. Although studies on L2 or foreign language attrition are inconclusive, researchers agree that the process is not linear and sets in rapidly, targeting the loss of productive skills such as speaking and writing [11].

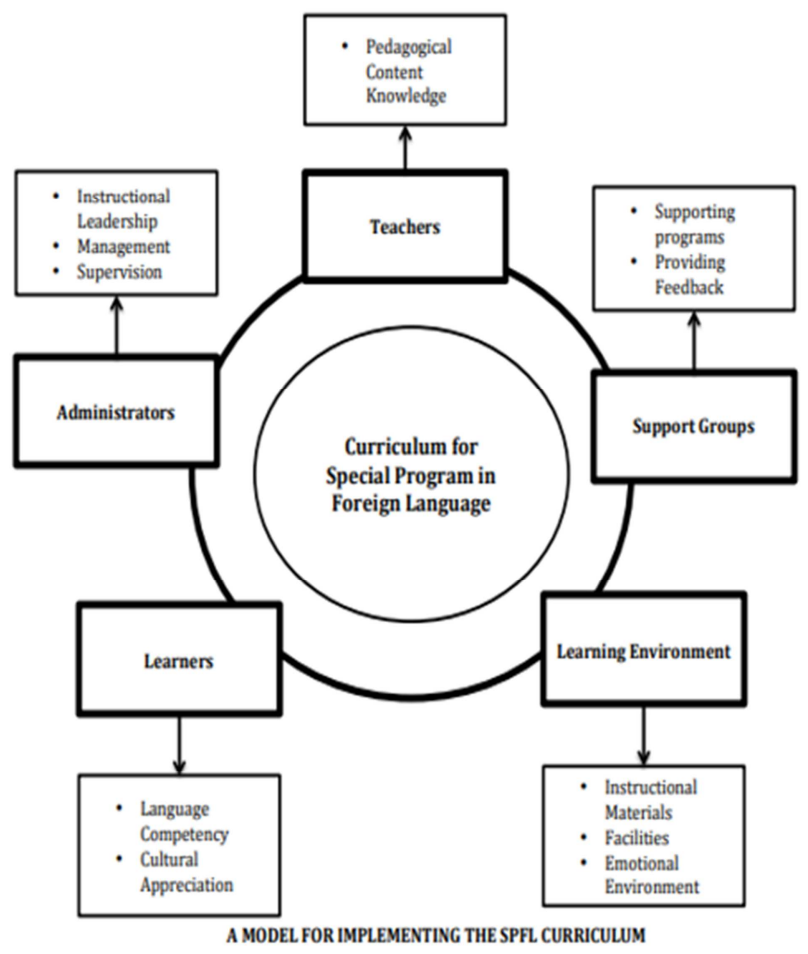

Figure 1. A Model for Implementing SPFL Curriculum.

Also particularly worth noting is the discrepancy between teacher- and principal-participants' report of the challenges in program implementation. As can be seen in the findings, teachers observed more serious problems than principals. This may imply that challenges are more likely to be experienced by teachers - the primary users of the curriculum, which in turn is central to the SPFL. This may be expected as administrators like principals may not be able to zoom into the issues present at the teacher-level. However, the incongruence between teacher and principal perception may lead to infidelity in policy and curriculum implementation. As the primary driver of any school-based program, it is imperative that principals are made aware of existing problems so that they may take action to solve these.
As a result, not only students, but more so teachers will benefit from an improved approach $[2,10]$.

In light of these issues disclosed by the current study, a model for the enhanced implementation of the SPFL is hereby proposed.

\subsection{Model for Implementing SPFL Curriculum}

The model for implementing SPFL curriculum is cyclic in structure and includes four agents of implementation coined as "drivers", which include students, teachers, administration and support group. Each of them has a specific description synchronized with the practices needed for the effective implementation of SPFL.

\section{Conclusion}

The research participants generally expressed satisfaction with the national foreign language foreign language program, particularly in terms of its objectives, curriculum, instruction, and assessment. Although there is no significant difference between the assessment of teachers and principals on the implementation status of SPFL, the difference in their views of the program's challenges should still be noted. The proposed model for better implementation of SPFL requires the involvement of four main agents with respective tasks to practice.

The current study provides invaluable insights into the ways the SPFL can move forward. However, it is not without limits. For one, the participants of the study, specifically the teachers and principals, upon knowing that the researchers are from the National Office of the DepEd, may have answered with the intention of protecting their respective schools from recrimination, and may therefore not have been completely honest despite the anonymity of their participation. This leads to the second point, which emphasizes the significance of ensuring the validity of data gathered. This may be achieved through triangulation or employing another set of data which will serve to corroborate initial findings. Finally, aspects of the questionnaire could have been further improved as has been discussed earlier. Doing so will more effectively address the question of whether or not the program was a success.

Nonetheless, the current study is successful in examining the many aspects of the national foreign language program, and obtaining important information for its enhancement in succeeding academic years.

\section{Recommendations}

In light of the results of the study, the following recommendations are raised:

1. Revisit the program implementation with the aim of modifying aspects needing enhancement, while sustaining positively observed profiles.

2. Devise scheme or strategies that will enhance the learners' satisfaction level to foreign language use. Sustain practices in assessment procedures. 
3. Conduct continuous monitoring of the program implementation to validate the findings of the study which is also significant in gathering input to policy development of SPFL implementation.

4. Teachers and principals as well as the other stakeholders may continue to collaborate in enhancing the implementation of SPFL.

5. Encountered challenges in the program implementation of SPFL may be reviewed for enhance purposes and may be viewed as significant entries to the modification of the program implementation.

6. The model for implementing SPFL curriculum may be utilized and serve as guide to implementers to may uphold SPFL standards and produce proficient.

\section{Acknowledgements}

The study would not have been possible without the help and cooperation of a number of stakeholders.

First and foremost, to the head of the Department of Education (DepEd), Secretary Leonor Magtolis Briones, for the great opportunity and honor to work and conduct this survey under her guidance.

To the Undersecretary for Curriculum and Instruction (CI), Usec. Diosdado M. San Antonio for his inspiring guidance and enlightenment to push through with this study.

To the Assistant Secretary for Curriculum and Instruction (CI), Asec. Alma Ruby C. Torio, for her unwavering support and guidance.

To the Director IV of the Bureau of Curriculum Development (BCD), Director Jocelyn DR Andaya, the researchers are grateful for her support in the endeavor to create an empirically based means of enhancing the Special Program in Foreign Language (SPFL). Her insights on the paper's development, from its inception to the final stages of its completion, have been paramount to its success.

To the Director III of the Bureau of Curriculum and Development (BCD), Director Samuel R. Soliven for his enduring patience, technical assistance, and generous and valuable suggestions provided to the researchers.

To the Chiefs of the Divisions - the Special Curricular Programs Division and the Curriculum Standards Development Division, headed by Ms. Rosa Ligaya Domingo and Dr. Isabel Victorino respectively, also played a significant role in crafting the study with their unparalleled encouragement in this research effort despite the notoriously hectic schedule and numerous other equally important priorities.

Noteworthy to mention is the unending support of the field officials and SPFL implementers, the Regional Directors (RDs)_Assistant Regional Directors (ARDs), Schools Divisions Superintendents (SDSs), Assistant Schools Division Superintendents (ASDSs), Division and Regional Supervisors, School Heads, Teachers and Students. The researchers are thankful for their immediate responses, cooperation, and assistance in accomplishing the survey instruments with zeal.
The researchers appreciate the very candid critical review and insights, valuable assistance, guidance and unyielding support of the following research consultants, Dr. Louiegrace Margallo and Dr. Realiza Mame.

Finally, this paper is a product, not only of the hard work of the researchers, but more so because of the grace of God. The fruit of this hard work is for the betterment of service to His children, and for the glory of His name.

\section{References}

[1] Abbott, M. (2018). Beyond a bridge to understanding the benefits of second language learning. American Educator, 39-43. Retrieved from https://files.eric.ed.gov/fulltext/EJ1182083.pdf.

[2] Cutter, C. (2017). The principal's role in the implementation of a one-to-one initiative: A case study of two schools [Doctoral dissertation]. University of Tennessee.

[3] Delhumeau, H. (2011). Language and globalization. Retrieved from https://hdelhumeau.wordpress.com/2011/07/22/languageand-globalization/.

[4] Department of Education Order No. 560, s. 2008. Special Program in Foreign Language. Pasig City: DepEd.

[5] Department of Education Order No. 55, s. 2009 Guidelines on offering foreign languages like Spanish, French, and Nihongo (Japanese) as elective subjects in the third and fourth year levels of high school. Pasig City: DepEd.

[6] Department of Education Order No. 5, s. 2015. Integration of travel expenses of SPFL teachers attending local training on teaching foreign language in the region/division/school budget. Pasig City: DepEd.

[7] Enhanced Basic Education Act 2013. (Phils).

[8] Kupske, F. (2020). The impact of language attrition on language teaching: the dynamics of linguistic knowledge retention and maintenance in multilingualism. Ilha Desterro, 72 (3). Retrieved from http://orcid.org/0000-0002-0616$612 \mathrm{X}$.

[9] O’Brien, M., Bajt, A., Lee, J., Lisanik, M., Pletnyova, A., \& Reyes, S. (2017). Literature review on the impact of secondlanguage learning. Retrieved from https://www.caslt.org/files/media/news/Lit-review-ImpactL2-Learning.pdf.

[10] Rigby, J., Forman, S., \& Lewis, R. (2019). Principals' leadership moves to implement a discipline-specific instructional improvement policy. Leadership and Policy in Schools. DOI: 10.1080/15700763.2019.1668422.

[11] Schmid, M. \& Mehotcheva, T. (2012). Foreign language attrition. Dutch Journal of Applied Linguistics. DOI: 1.10.1075/dujal.1.1.08sch.

[12] Stein-Smith, K. (2017). The multilingual advantage: Foreign language as a social skill in a globalized world. International Journal of Humanities and Social Science, 7 (3). Retrieved from

https://www.ijhssnet.com/journals/Vol_7_No_3_March_201 7/6.pdf. 
Program in Public Secondary Schools

[13] Sun, J. (2013). Globalization and language teaching and learning in China. International Journal on Integrating Technology in Education, 2 (4). Retrieved from http://airccse.org/journal/ijite/papers/2413ijite04.pdf.

[14] World Economic Forum (2017). How learning a new language makes you more tolerant [Video file]. https://fbvideodownloader.info/videos/10154065567466479.

[15] Wu, S. (2019). Implementation of Special Program in Foreign Language (SPFL) [Unpublished doctoral dissertation]. Pangasinan State University. 